\title{
A Comparison of the Requirements of University Library Quality Assurance System with Internationally Recognized ISO 9001:2000 and ISO 9001:2008 Quality Management Systems
}

Harshani N.K. Dissanayake*

BSc (Hons)(Peradeniya), MPhil(Peradeniya), MLS(Colombo)

\begin{abstract}
Providing a quality service has become a must in the library and information science sector today. The readers expect an effective and efficient library service from the library staff. Therefore providing a customer oriented service has become a challenge to the librarians and information professionals.

The University Grants Commission has initiated a Quality Assurance System for all the faculties and the academic libraries of the Universities under the World Bank project, Improving Relevance and Quality of Undergraduate Education (IRQUE).

The quality management systems (QMS) ISO 9001:2000 and ISO 9001:2008 are internationally recognized Quality Management Systems. They have been successfully implemented in some Sri Lankan libraries to provide an effective service to the library users.

A comparison of the requirements of the University Library Quality Assurance System and the two international standards is carried out in this study.
\end{abstract}

Key words: Quality Management System, ISO 9001:2000, ISO

9001:2008, Academic Libraries, Sri Lanka

\section{Introduction}

The library users in today's context expect an effective and efficient service. Providing information for them to satisfy their requirements has become a challenge for librarians and information professionals.

\footnotetext{
"Senior Assistant Librarian, Main Library, University of Peradeniya E-mail: harshanid@pdn.ac.lk
} 
With the new developments in information technology, the library functions are being subjected to a wide transformation from its conventional role to suit new environments. Therefore it is important to pay attention to manage the libraries and information centers effectively to provide the maximum services to its users with the available resources. Quality management has been applied within the manufacturing industry for over two decades.

Later the service industry too worked towards this. (Hsieh, 2000) Now most of the private and public sector organizations have adopted various quality management systems to provide a quality service to their customers.

Observing the effectiveness and the positive impact on customer's in these organizations, the libraries in Sri Lanka too started to venture on implementing Quality Management Systems.

As libraries provide services to their readers these Quality Management Systems could be successfully implemented in library environments too. (Jayasundara, 2003) Few special libraries in Sri Lanka have received certificates for standardizing their services as their parent organization worked towards ISO standardization. (Dissanayake et.al., 2007) The University Libraries too have ventured towards providing a quality service to their academic community. The University libraries have introduced Quality Assurance and Accreditation under the World Bank project, Improving Relevance and Quality of Undergraduate Education (IRQUE).

\section{The University Library Quality Assurance System-}

The University Library Quality Assurance System considers eight aspects in evaluation of libraries. They are; 
1. Mission and Goals-

Mission, goals and objectives serve as the frame work for activities of the University Library Quality Assurance System.

2. Management -

Set procedures and mechanisms in normal library activities and responsibility, authority and accountability of staff members in rendering their duties are evaluated here.

3. Resources-

Management of physical resources, human resources and library resources is considered.

4. Services-

Library services to support University's mission and goals, the services provided for the users, use of new technology in providing the services are considered here.

5. Integration -

Integration with other faculties in their academic work and with University management process by taking part in various committees etc. is evaluated.

6. Contribution to academic output-

The role of library in academic out put in the area of developing information skills of the staff and students of the University.

7. Networking-

Corporation with other libraries in providing services and the use of Information Technology in providing remote access etc,

8. Evaluation-

Evaluation of library services by user surveys, interviews and requesting for comments and suggestions. (Quality Assurance Hand book for Sri Lankan University Libraries, 2007) 


\section{ISO Quality Management System (QMS)}

According to ISO quality management system, if an organization expects to implement a quality management system, there should be a formal quality system. This system should provide confidence for the employees to propel forward. It should operate efficiently and effectively to provide a quality product to meet customer expectations. In an effective quality system prevention is considered better than detection. There are number of formal quality management systems published by International Organization for Standardization (ISO). ISO 9000 series is one of them.

ISO 9000 is a series of standards on quality assurance and quality management systems published by ISO in 1987 . This is an internationally recognized standard. This standard deals with the quality management of the organization and is subjected to interpretation in different environments such as industry, service sector etc. This system may be applied to any organization or any situation. The standard focuses on key quality management principles, customer satisfaction and continual improvement.

ISO 9000 standards first revised in 1994 and then in 2000 and 2008. There are three main documents in ISO 9000:2000 family. (Mendis, 2002)

They are;

- ISO 9000 : 2000 -Quality Management Systems-

Fundamentals and vocabulary

(ISO 9000:2000- Quality Management Systems- Fundamentals and vocabulary, 2000)

- ISO 9001 : 2000-Quality Management Systems-

Requirements

(ISO 9001: 2000- Quality Management Systems-Requirements, 2000) 
- ISO 9004 : 2000 -Quality Management Systems - Guidelines for performance improvements

(ISO 9004: 2000 - Quality Management systems -Guidelines for improvements, 2000)

ISO $9001: 2000$ is the document which specifies the requirements of the system.

The essential features of ISO 9001:2000 are

- Customer focus

- Process approach

- Continual improvement

\section{Customer focus}

Organizations depend on their customers. Therefore it is important to understand their requirements, meet their expectations and exceed them.

\section{Process approach}

ISO $9001: 2000$ is based on application of a system of processes. Identification and interactions of these processes is an essential component. The desired outcome is obtained by managing the processes effectively.

\section{Continual improvement}

Continuous improvement is achieved by implementing the application of process approach and monitoring and measurement of them in an effective manner.

(Dharmadasa, 2002) 


\section{ISO 9001:2000 Quality Management System (Requirements)}

There are eight clauses in the standard. (ISO 9001: 2000- Quality Management Systems- Requirements, 2000)

\section{Scope-}

The organizations should apply all the requirements given in the standard regardless of the type, size and product provided. Exclusions are allowed only if they are limited to the requirements within the clause 7 i.e. product realization by furnishing valid reasons for excluding them. The clauses are common for all types of organizations in this system. In University Library Quality Assurance System the requirements are specifically made to suit the academic libraries. Therefore it is mandatory to fulfill the requirements specified in the handbook.

\section{Normative documents -}

The reference documents which are used in application of this standard. For ISO 9001:2000 the reference document is ISO 9000:2000, Quality Management Systems Fundamentals and Vocabulary. ISO 9000:2005 is the normative reference for ISO 9001:2008. (Quality Management Systems - Fundamentals and Vocabulary, 2005)The normative reference standard provides the clarifications to clauses given in the system requirements standard. ISO systems are common to any type of organization and therefore the requirements have to be clearly understood when applying them for an organization.

In the University Library Quality Assurance System the eight requirements are specifically focused to library environment and therefore they can be clearly understood by the professional staff members of the library. There is no requirement to have a separate normative document in this system. 


\section{Terms and definition -}

The terms and definitions given in the respective ISO 9000 document (normative document) have to be used. In this quality management system the word "product" includes the word "service" too.

The relevant technical terms used in Library and Information Science are used in the preparation of self evaluation report.

\section{Quality Management System (QMS)-}

There are general requirements and documentation requirements.

In the University Quality Assurance System, the requirements are not divided as general and documentation but the both are addressed within one system.

\section{The general requirements -}

The general requirements are the basic requirements needed to implement the QMS. The organization has to determine the processes needed for QMS, their sequence and interaction, the operation and control of these processes and monitor, measure and analyze these processes. The continual improvement is achieved by implementing all these process.

The key business process and support processes of the organization are identified in this clause. The sequence and interaction of these processes has to be shown in a diagram in the Quality Manual.

In the University system the processes are identified but they are not divided as key business process and support processes. Their sequence and interaction is also not considered here. The requirements under the chapters, Resources, Services, Integration, Contribution to Academic out put and Networking can be considered as key business processes. 


\section{The Documentation requirements-}

There are two types of documents involved in the QMS system. They are:

- Policy documents, documented procedures and records required by the standard.

Documents needed by the organization to ensure the effective planning, operation and control of its processes.

These documents in the QMS are divided as Level 1, Level 11 and Level 111 documents.

- The Level 1 documents - Policy documents.

Quality manual is a policy document. The organization has to declare their policies towards the requirements of the clauses in the standard. e.g-
6.2 - Infrastructure and Work Environment
Policy - The library building is centrally located for the convenience of the users. Different types of information material are arranged in separate sections according to a specified order for easy location. A pleasant and silent environment is maintained in the library Computer facilities are provided for library readers.

Separate work stations are provided for the library staff.

In the University Library Quality Assurance System a self evaluation report is prepared addressing all the requirements stated in the handbook. The policies are also included in this report. Therefore a separate policy document is not a requirement. 
- The level 11 documents-

Procedures are considered as level 11 documents.

There are two kinds of procedures.

A. The procedures needed for effective functioning of the organization or working procedures. The organization has to identify the key business processes and support services. E.g. in a library, processing of library materials can be identified as a key business process and photocopy service can be identified as a support process.

B. The second type of documents is procedures required by the international standard. There are six essential documented procedures required by the standard.

- Control of documents

- Control of records

- Control of non conformities

- Internal audits

- Corrective action

- Preventive action

In the University Library Quality Assurance System, procedures are described under resources, services, integration, contributions to academic output and networking. Different service divisions of the library maintain separate files of their respective procedures. The second type of documents i.e. procedures required by the standard is not a requirement in the University Accreditation System.

Level 111 documents are work instructions, guidelines etc. 
These documents are not mentioned as a requirement in the University Library Quality Assurance system.

\section{Management responsibility}

In the ISO system the top management should show their commitment towards the development and implementation of QMS. They have to communicate the importance of meeting customers as well as statutory and regulatory requirements. A member of the management is appointed as the management representative to establish the QMS. Top management is responsible in establishing a quality policy and quality objectives, conducting management reviews and ensuring resources. The quality policy should be appropriate to the purpose of the organization and should provide the frame work for quality objectives. Progress of the quality system is examined at management review meetings. The resource needs are also discussed at these meetings.

In ISO 9001:2000 a separate quality policy is established. This is prepared by considering the vision, mission and objectives of the organization. There are Quality Objectives derived from the Quality Policy. The Quality Policy and Quality Objectives provide the framework for the QMS. The Quality Policy has to be displayed in the organization.

In the University Library Quality Assurance System, the vision, mission and objectives of the library provide the frame work for the quality system. The Librarian is responsible for the implementation of the quality system. The management review with the top management at regular intervals is not a requirement in the University Library Quality Assurance System. Defining the responsibilities and authority of library staff is common in both systems. 


\section{Resource Management}

Human resource, infrastructure and work environment are the major components under this clause. The requirements for human resource development, identification of training needs, evaluation of training comes under human resources. The records of education, training skills and experience of individual employees have to be maintained. Buildings, work place, process equipment and associated utilities too come under infrastructure. The requirement of a proper working environment is also addressed in the standard.

In the University Library Quality Assurance System the same is addressed in resources chapter. Additionally the library resource management is included in this chapter.

\section{Product realization}

Planning of product realization, customer related process, design and development, Purchasing, Control of monitoring and measuring devices come under this clause. If any of these sub clauses are not relevant to a particular organization they can be excluded from the QMS by furnishing valid reasons. E.g. Control of monitoring and measuring devices is not relevant to libraries.

In the University Library Accreditation System, the planning of product realization is not a specified requirement but it is included in the resources, services, integration, contribution to academic output and networking chapters. Customer related process is discussed in the evaluation chapter.

\section{Measurement, Analysis and improvement}

Monitoring and measurement, control of non conforming product, analysis of data and improvement are the requirements of this clause. Monitoring and 
measurement of customer satisfaction, conduct of regular internal audits, and monitoring and measurement of processes comes under monitoring and measurement. The organization should maintain records of customer satisfaction. E.g. User surveys.

Internal audits are done by internal staff of the organization, attached to other divisions. The audits should be conducted at regular intervals. Quality policy, quality objectives, all the manuals and procedures are audited against the standard to check whether the requirements are addressed.

The processes have to be monitored and measured. For each process there should be a way of measuring it. The non conforming products are deviations from the system. If a set procedure is not running as it is stated in the document it is a non conformity. Therefore there should be a way of controlling this. There should be documented evidence to show the actions taken in controlling the non conformities. Corrective actions are taken to rectify the non conformities of the system. The root cause of the non conformity is studied before taking the action. There should be certain preventive actions taken to prevent occurring errors. E.g. double checking of a catalogued book. All these corrective and preventive actions contribute to the continual improvement of the QMS. Through continual improvement of internal processes, a better service can be provided to the customer.

The monitoring and measurement is a very strong area in ISO quality management system. Every quality objective which derive from Quality Policy should be monitored either qualitative or quantitatively. QMS system processes also should be monitored. The customer satisfaction should be monitored at regular intervals. It is mandatory to show documentary evidence of the analysis of monitoring and measurement results. They have to be filed 
systematically. The results will be discussed at the Management Review meetings. The results of monitoring and measurement processes, results of internal audits and output of management review are considered for continual improvement of the system. It is a requirement to show how the library services and products are improved using these data.

In the university quality accreditation system this is included in the evaluation chapter. Although the continual improvement is mentioned in the introduction, it is not clearly stated in the evaluation chapter about the use of statistics for continuous improvement of the library.

The ISO $9001: 2000$ will be replaced by ISO $9001: 2008$. The current standard amends the former standard and clarifies the points in the text. The basic requirements for QMS are almost the same in both standards. (ISO 9001 : 2008-Quality Management Systems- Requirements)

\section{Conclusion}

The University library quality assurance system and ISO 9001:2000 system requirements have both similarities and differences in their requirements. Two systems are based on eight major requirements. The documentation requirements are different in two systems. Almost all the requirements of the University Library Quality Assurance System are included in the ISO 9001:2000 Quality Management System. There are additional requirements to be addressed in the University Library Quality Assurance System to reach the international ISO standard. Theses areas could be defined as identification of key business processes and support processes in the library bringing them to a single platform by considering the sequence and interactions of these processes, management review, internal audits, stronger monitoring and 
measurement processes and the defined paths to achieve continuous improvement.

\section{References}

Dharmadasa, D. (2002) Quality Management, Challenges for Librarians: Seminar on Quality Management Challenges for Librarians organized by the special libraries' group of Sri Lanka Library Association. Colombo: Sri Lanka Library Association.

Dissanayake, H.N.K. et.al. (2007) Introduction of ISO 9001:2000 Quality Management System to Library and Information Services: A Case Study, Sri Lanka Library Review 21, 22-36.

Hsieh Pao-Nuan and Chang Pao-Long et.al (2000) Quality Management Approaches in Libraries and Information Services, Libri 30, 191-201

ISO 9000 : 2000- Quality Management Systems- Fundamentals and vocabulary (2000) Colombo: Sri Lanka Standards Institution.

ISO 9001 : 2000- Quality Management Systems- Requirements. $3^{\text {rd }}$ ed.(2000) Colombo: Sri Lanka Standards Institution.

ISO 9004:2000 - Quality Management systems -Guidelines for improvements,. $2^{\text {nd }}$ ed. (2000) Colombo: Sri Lanka Standards Institution.

ISO 9001:2005-Quality Management Systems : Fundamentals and Vocabulary, $3^{\text {rd }}$ ed. (2005) Colombo: Sri Lanka Standards Institution

ISO 9001 : 2008- Quality Management Systems- Requirements. $4^{\text {th }}$ ed.(2008) Colombo: Sri Lanka Standards Institution.

Jayasundara, C.C. (2003) Implementing ISO 9000 in modern library and information service sector: a management writing for the development of high quality library service. Journal of the University Librarians' Association of Sri Lanka. 7, 56-66

Mendis, B.S.P. (2002) Introduction to ISO 9000:2000 series of standards and concepts of quality systems, Seminar on ISO 9001:2000 standard and the preparation of quality manual. Colombo: Sri Lanka Standards Institution 
Quality Assurance Hand Book for Sri Lankan University Libraries (2007), Colombo: Quality Assurance and Accreditation council. 